\title{
Establishment and characterization of a cisplatin-resistant human osteosarcoma cell line
}

\author{
TAO HAN ${ }^{1,2^{*}}$, XIAOMING ZHU ${ }^{3,4^{*}}$, JULEI WANG $^{5^{*}}$, HAIEN ZHAO $^{1}$, QIONG MA $^{1}$, \\ JIAN ZHAO $^{1}$, XIUCHUN QIU ${ }^{1}$ and QINGYU FAN ${ }^{1}$ \\ ${ }^{1}$ Department of Orthopedic Surgery, Tangdu Hospital, Fourth Military Medical University, Xi'an, Shanxi 710038; \\ ${ }^{2}$ Department of Orthopedic Surgery, Hainan Branch of PLA General Hospital, Sanya, Hainan 572013; \\ ${ }^{3}$ Department of Obstetrics and Gynecology, Tangdu Hospital, Fourth Military Medical University, Xi'an, Shanxi 710038; \\ ${ }^{4}$ Department of Gynecology and Obstetrics, General Hospital Chinese PLA, Beijing 100853; ${ }^{5}$ Department of \\ Neurosurgery, Tangdu Hospital, Fourth Military Medical University, Xi'an, Shanxi 710038, P.R. China
}

Received April 23, 2014; Accepted May 23, 2014

DOI: 10.3892/or.2014.3314

\begin{abstract}
The aim of the present study was to establish a new cisplatin-resistant human osteosarcoma cell line and investigate its biological characteristics. The human osteosarcoma cell line SOSP-9607 was exposed to cisplatin by stepwisely increasing the concentrations in the medium to select for the drug-resistant subline, SOSP-9607/CDDP cells. The morphological features were observed using inverted microscopy. The growth curves of SOSP-9607 and SOSP-9607/CDDP cells were drawn to calculate the doubling time. FCM was also used to determine the distribution of the cell cycle. The MTT assay was performed to test the drug resistance of SOSP9607 and SOSP-9607/CDDP cells. Transwell assay was used to examine the invasive capability of the SOSP-9607/CDDP and SOSP-9607 cells. RT-PCR was performed to determine the mRNA expression levels of drug resistance-related and apoptosis-related genes, MDR1, MRP1, MRP2, LRP, ABCG2, GST- $\pi$, Bcl-2 and Bax, in both cell lines. SOSP-9607/CDDP cells exhibited changes in morphology, proliferation rate, doubling time, cell cycle distribution and invasive capability as compared with the SOSP-9607 cells. SOSP-9607/CDDP cells were 6.24-fold resistant to cisplatin in comparison with the SOSP-9607 cells and also exhibited cross-resistance to methotrexate and adriamycin. SOSP-9607/CDDP cells overex-
\end{abstract}

Correspondence to: Professor Qingyu Fan or Professor Xiuchun Qiu, Department of Orthopedic Surgery, Tangdu Hospital, Fourth Military Medical University, 1 Xinyi Road, Xi'an, Shanxi 710038, P.R. China

E-mail: fanqingyutd@163.com

E-mail: qiuxiuchuntd@163.com

${ }^{*}$ Contributed equally

Key words: osteosarcoma, cisplatin, multidrug resistance pressed MRP1, MRP2 and GST- $\pi$. In conclusion, SOSP-9607/ CDDP cells are invaluable tools with which to study the resistance of anticancer drugs and to identify the methods to overcome resistance.

\section{Introduction}

Osteosarcoma is a rare highly malignant bone tumor that occurs predominantly in adolescents and young adults. A defining feature of osteosarcoma is the high rate of metastasis and the most common site of metastasis is the lungs. In the era before the use of chemotherapy, over $85 \%$ of post-surgery patients developed metastases (1). Chemotherapy routinely plays an important role in the treatment of advanced osteosarcoma. At present, although the percentage of patients cured has increased between 60 and $70 \%$ by neoadjuvant chemotherapy coupled with limb-sparing surgery, the prognosis remains poor for most patients with metastatic or recurrent osteosarcoma (2). This poor prognosis is mostly due to the development of drug resistance by osteosarcoma cells after chemotherapy. Cisplatin or cis-diamminedichloroplatinum (II) (CDDP) is one of the most active anticancer agents, widely used against various tumors including osteosarcoma. The mechanism of cisplatin anticancer activity is generally believed to be its binding to DNA, interfering with the cell repair mechanism, eventually leading to cell death (3). However, the success of chemotherapy depends on the sensitivity of the tumor to CDDP, as osteosarcoma cells often acquire resistance to drugs and even develop multiple drug resistance, which results in treatment failure. In this regard, CDDP resistance has become one of the major clinical issue to overcome. Alhough extensive research has been carried out concerning the resistance to CDDP, there is no mechanism to completely explain the clinical response to CDDP therapy. For the purpose of fully understanding drug resistance, establishment of cultured cell lines resistant to anticancer drugs is primarily necessary. In the present study, we established a human osteosarcoma subline resistant to CDDP and examined the characteristics and mechanisms of CDDP resistance in this cell line. 


\section{Materials and methods}

Anticancer agents. CDDP was purchased from Hansoh Pharmaceutical Co. (Lianyungang, China) and stored at a concentration of $1 \mathrm{mg} / \mathrm{ml}$ at room temperature. Methotrexate (MTX) was purchased from Hualian Pharmaceutical Co. (Shanghai, China) and stored at a concentration of $1 \mathrm{mg} / \mathrm{ml}$ diluted in $0.9 \% \mathrm{NaCl}$ at $-20^{\circ} \mathrm{C}$. Adriamycin (ADM) was purchased from Hisun Pharmaceutical Co. (Taizhou, China) and stored at a concentration of $2 \mathrm{mg} / \mathrm{ml}$ diluted in $0.9 \%$ $\mathrm{NaCl}$ at $-20^{\circ} \mathrm{C}$. Paclitaxel (PTX) was purchased from BristolMyers Squibb (Shanghai, China) and stored at a concentration of $6 \mathrm{mg} / \mathrm{ml}$ at $-20^{\circ} \mathrm{C}$.

Cells and cell culture. The human osteosarcoma cell line SOSP-9607 was established in our laboratory as described previously (4). The cells were cultured in RPMI-1640 medium (HyClone, USA) supplemented with $10 \%$ fetal calf serum (FCS; Sijiqing Co.), $100 \mathrm{U} / \mathrm{ml}$ of penicillin $\mathrm{G}$ and $100 \mu \mathrm{g} / \mathrm{ml}$ of streptomycin, in a humidified atmosphere of $5 \% \mathrm{CO}_{2}$ at $37^{\circ} \mathrm{C}$. CDDP-resistant cells were established by stepwisely increasing the concentrations of CDDP in the medium (5). CDDP was added to the cells at concentrations from $0.1,0.2,0.5,1$ to $2 \mu \mathrm{g} / \mathrm{ml}$ when they grew to $60-70 \%$ confluency. After continuous exposure to CDDP for 2 days, the medium was replaced with a fresh CDDP-free medium until the surviving cells recovered favorably. When cells grew to the same confluency, CDDP was added to the medium again. Each concentration was repeated six times. After 12 months, cells that grew in the medium with $2 \mu \mathrm{g} / \mathrm{ml}$ of CDDP were designated as SOSP-9607/CDDP cells and stored for further investigation.

Growth curves and the doubling time $\left(T_{d}\right)$. The cells in an exponential growth phase $\left(1 \times 10^{5} / 5 \mathrm{ml}\right)$ were seeded in a $60-\mathrm{mm}$ plastic dish. The numbers of cells were counted using a hemocytometer every $24 \mathrm{~h}$ for 7 days. The growth curve was plotted using the average number of cells from triplicate plastic dishes. The doubling time $\left(\mathrm{T}_{\mathrm{d}}\right)$ of each cell line was counted according to the formula: $\mathrm{T}_{\mathrm{d}}=\Delta \mathrm{t} \times \lg 2 /\left(\lg \mathrm{N}_{\mathrm{t}}-\lg \mathrm{N}_{0}\right)$; where $\mathrm{N}_{0}$ is the cell number at the beginning and $\mathrm{N}_{\mathrm{t}}$ is the cell number at the end, and $\Delta \mathrm{t}$ is the time from $\mathrm{N}_{0}$ to $\mathrm{N}_{\mathrm{t}}$.

Cell cycle analysis by flow cytometry. The SOSP-9607 and SOSP-9607/CDDP cells in the logorithmic phase of growth were collected following trypsin digestion. The cells were washed with PBS and fixed in $70 \%$ ethanol at $4^{\circ} \mathrm{C}$ overnight. The fixed cells were washed with cold PBS and stained with $50 \mathrm{mg} / \mathrm{ml}$ DNA-binding dye propidium iodide (PI; Sigma-Aldrich, St. Louis, MO, USA) and $1.0 \mathrm{mg} / \mathrm{ml}$ RNase (Invitrogen, Carlsbad, CA, USA) for $30 \mathrm{~min}$ at $37^{\circ} \mathrm{C}$ in the darkness and examined with a fluorescence-activated cell sorting (FACS) flow cytometer (BD Biosciences, San Jose, CA, USA). Each test was repeated in triplicate.

Drug sensitivity assay. The 3-(4,5-dimethyl-2-thiazol) -2,5-diphenyl-2H tetrazolium bromide (MTT) assay was applied to determine the sensitivities of the cell lines SOSP-9607 and SOSP-9607/CDDP to the drugs CDDP, MTX, PTX and ADM. Monodispersed cells in the exponential growth phase following trypsinization were plated into 96-well plates at $5 \times 10^{3} /$ well. After an overnight incubation, the medium was replaced with a fresh one containing various concentrations of the drugs mentioned above. Eight different concentrations for each drug were used in triplicate wells. Drug-free medium was added to the control and blank wells. After the plates were incubated for $72 \mathrm{~h}, 20 \mu 1$ of $5 \%$ MTT was added to each well for $4 \mathrm{~h}$ at $37^{\circ} \mathrm{C}$. Then the MTT solution was removed, and the insoluble formazan crystals were dissolved in $150 \mu \mathrm{l}$ of dimethylsulfoxide (DMSO; Sigma). The absorbance was measured at wavelengths of 490 and $630 \mathrm{~nm}$ using a Multiskan Ascent microplate photometer (Thermo Labsystems, USA). Resistance indices (RIs) were calculated by the ratio of the $50 \%$ inhibitory concentration $\left(\mathrm{IC}_{50}\right)$ values of the SOSP-9607/CDDP to SOSP-9607 cells.

Invasive capability of the cells. Transwell assay was used to examine the invasive capability of the SOSP-9607/CDDP and SOSP-9607 cells. The $6.5-\mathrm{mm}$ Transwell insert (pore size, $8 \mu \mathrm{m}$; 24-well insert; Corning) was pre-coated with $40 \mu \mathrm{l}$ BD Matrigel (1:8 dilution, BD Biosciences). The cells were inoculated on the filter at a density of $5 \times 10^{4}$ cells/filter and incubated with serum-free medium for $48 \mathrm{~h}$. The medium with $20 \%$ fetal bovine serum was added to the lower chamber outside of the insert. The cells that invaded through the Matrigel and reached the lower surface of the filter were fixed with $95 \%$ ethanol for $30 \mathrm{~min}$ and then stained with $0.1 \%$ crystal violet for $10 \mathrm{~min}$. The numbers of cells in 10 random fields were counted under a light microscope at x200 magnification and the average was calculated.

RT-PCR analysis. Total RNA was isolated from the cells in the exponential growth phase with TRIzol (Invitrogen). Complementary DNA (cDNA) was instructed by reverse transcription (RT) of $5 \mu \mathrm{g}$ each total RNA. Each cDNA sample was amplified with ExTaq (Takara, Japan). PCR reactions for the indicated genes were carried out using the following forward and reverse primers in Table I. The cycling conditions included: denaturing at $94^{\circ} \mathrm{C}$ for $5 \mathrm{~min}$, annealing at $55^{\circ} \mathrm{C}$ for $60 \mathrm{sec}$ and extension at $72^{\circ} \mathrm{C}$ for $60 \mathrm{sec}$, with total PCR cycles of 30 , with a final extension at $72^{\circ} \mathrm{C}$ for $10 \mathrm{~min}$. Each of the amplified PCR products was determined by electrophoresis on an $1.5 \%$ agarose gel. The PCR results were observed under a Molecular Imager ChemiDoc XRS System and analyzed with Quantity One Software (both from Bio-Rad, Hercules, CA, USA). The ratio of the band density of the PCR for the gene of interest and the housekeeping gene GAPDH was used as the quantitative index of equal loading of cDNA for PCR samples among the SOSP-9607 and SOSP-9607/CDDP cell lines.

Statistical analysis. Data are expressed as mean \pm standard deviation (SD) and the experiments were repeated three times. Continuous variables were analyzed using the Student's t-test. $\mathrm{P}<0.05$ was considered to indicate a statistically significant result. All statistical analyses were performed using SPSS 17.0 software (SPSS, Chicago, IL, USA).

\section{Results}

Establishment of the cisplatin-resistant cell line. We established SOSP-9607/CDDP cells by stepwise exposure methods 
Table I. Primers used for the RT-PCR analysis.

\begin{tabular}{lll}
\hline Gene & \multicolumn{1}{c}{ Forward } & \multicolumn{1}{c}{ Reverse } \\
\hline MDR1 & 5'-GAATCTGGAGGAAGACATGACC-3' & 5'-TCCAATTTTGTCACCAATTCC-3' \\
MRP1 & 5'-TCAGCCCTTCCTGACAAGCT-3' & 5'-TCTCTGCTGCAGGAGGTCCG-3' \\
MRP2 & 5'-TAGAGCTGGCCCTTGTACTC-3' & 5'-TCAACTTCCCAGACATCCTC-3' \\
LRP & 5'-CCCCCATACCACTATATCCATGTG-3' & 5'-TCGAAAAGCCACTCATCTCCTG-3' \\
ABCG2 & 5'-CAACCATTGCATCTTGGCTG-3' & 5'-CAAGGCCACGTGATTCTTCC-3' \\
GST- $\pi$ & 5'-CATGCTGCTGGCAGATCAGG-3' & 5'-CATTCATCATGTCCACCAGG-3' \\
Bcl-2 & 5'-ATGTCCAGCCAGCTGCACCTGAC-3' & 5'-GCAGAGTCTTCAGAGACAGCCAGG-3' \\
Bax & 5'-GCTTCAGGGTTTCATCCAGG-3' & 5'-AAAGTAGGAGAGGAGGCCGT-3' \\
GAPDH & 5'-ACCACCATGGAGAAGGCTGG-3' & 5'-CTCAGTGTAGCCCAGGATGC-3' \\
\hline
\end{tabular}
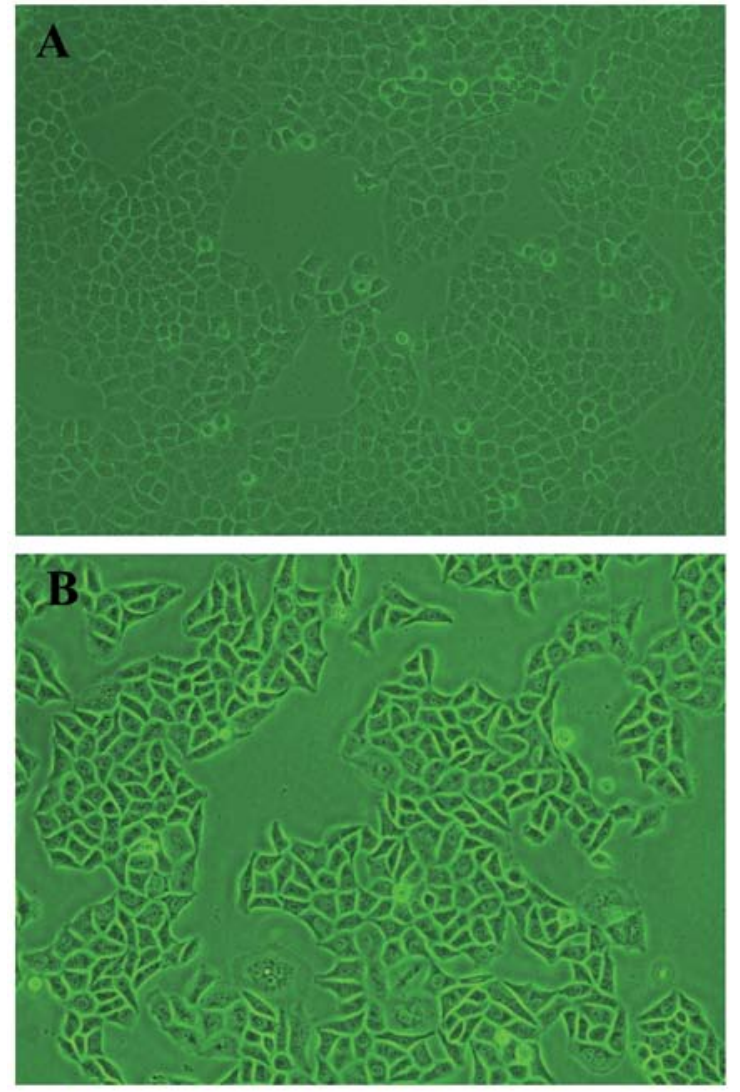

Figure 1. Morphology of (A) SOSP-9607 and (B) SOSP-9607/CDDP cells in the exponential growth phase. Morphological characteristics were determined using an inverted microscope at an original magnification of $\times 200$. SOSP-9607 cells were observed to be medium in volume, even in size and oval in shape with little cytoplasm and a clear nucleolus. SOSP-9607/CDDP cells are larger in volume and triangular or irregular in shape with a markedly enlarged nucleus and cytoplasm and more multiple nucleoli.

(from $0.1 \mu \mathrm{g} / \mathrm{ml}$ cisplatin) for 12 months. Under a light microscope, both SOSP-9607 and SOSP-9607/CDDP cells grew adhering to the bottom. SOSP-9607 cells were medium in volume, even in size and oval in shape with little cytoplasm and a clear nucleolus (Fig. 1A). SOSP-9607/CDDP cells are larger than the SOSP-9607 cells in volume and trianglular or irregular in shape with a markedly enlarged nucleus and cytoplasm, and more multiple nucleoli (Fig. 1B).

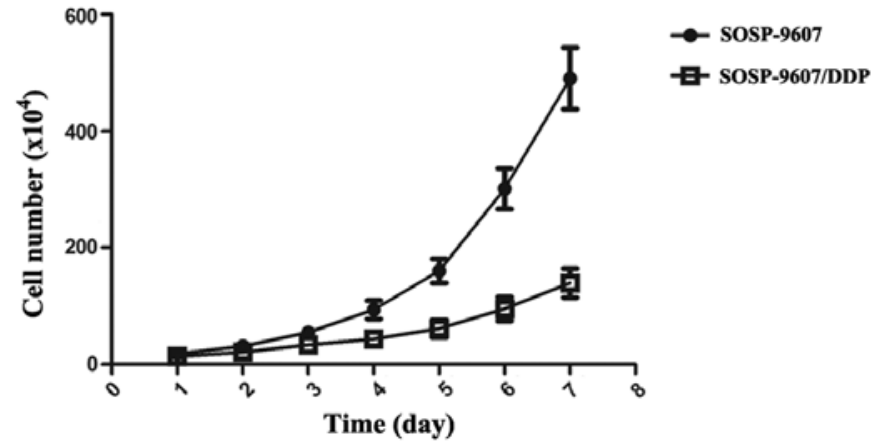

Figure 2. Growth curves of SOSP-9607 and SOSP-9607/CDDP cells. The cell growth curves were plotted with culture time on the $\mathrm{x}$-axis and the average cell counts/per day on the y-axis. The SOSP-9607/CDDP cells grew more slowly than their SOSP-9607 parental cells, with a decrease in the growth curve.

Growth curves and doubling time $\left(T_{d}\right)$. The cell growth curve was plotted with culture time on the $\mathrm{x}$-axis and the average cell counts/per day on the y-axis. The SOSP-9607/CDDP cells grew more slowly than their SOSP-9607 parental cells, with a decrease in growth curves. The resistant cell lines appeared to have a delay in the initiation of logarithmic growth. According to the cell growth curves (Fig. 2), the $\mathrm{T}_{\mathrm{d}}$ of SOSP-9607 and SOSP-9607/CDDP cells was $29.79 \pm 0.57$ and $45.11 \pm 2.37 \mathrm{~h}$, respectively, which was significantly different $(\mathrm{P}<0.01)$.

Cell cycle analysis. The cell cycle distribution was assessed with flow cytometry. As shown in Fig. 3, there were more SOSP-9607/CDDP cells in the $\mathrm{G}_{0} / \mathrm{G}_{1}$ phase and less in the $S$ phase as compared to the SOSP-9607 cells $(\mathrm{P}<0.05)$. There was no significant difference between the two cell lines in regards to the $\mathrm{G}_{2} / \mathrm{M}$ phase.

Drug sensitivity assay. The results of the MTT assays showed that the $\mathrm{IC}_{50}$ values for the SOSP-9607 and SOSP-9607/CDDP cells to CDDP were $2.45 \pm 0.27$ and $15.31 \pm 0.21 \mu \mathrm{g} / \mathrm{ml}$, respectively. The RI of the SOSP-9607/CDDP cells was 6.24 times, which means that this cell line was highly resistant to CDDP. The SOSP-9607/CDDP cells also had cross resistance to MTX and ADM, respectively, but showed no resistance to PTX (Table II). 

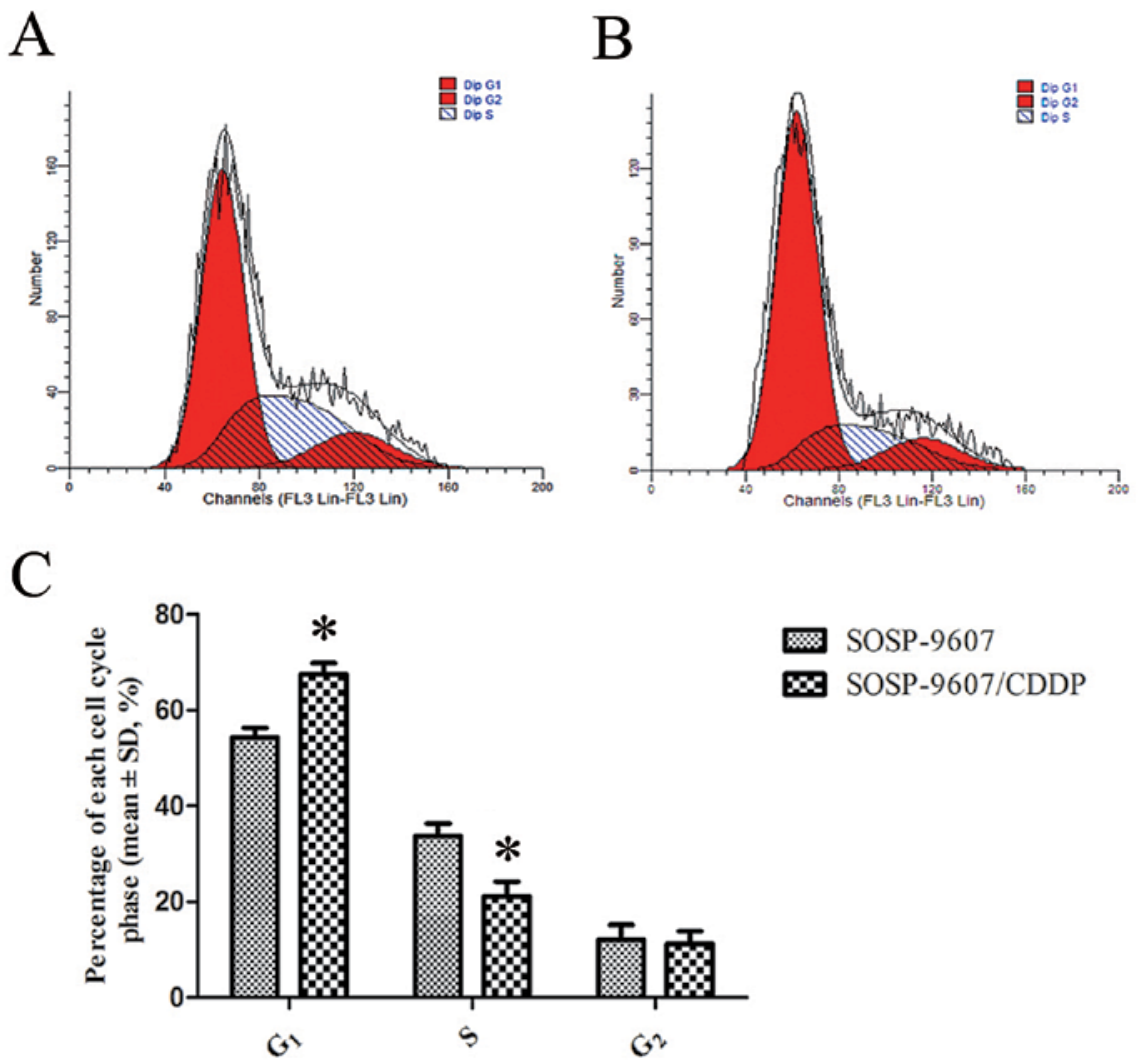

Figure 3. Cell cycle distribution of the (A) SOSP-9607 and (B) SOSP-9607/CDDP cells. (C) Flow cytometric data displayed in a histogram. Higher percentages of SOSP-9607/CDDP cells were noted in the $\mathrm{G}_{0} / \mathrm{G}_{1}$ phase and a lower percentage was noted in the $\mathrm{S}$ phase as compared to the SOSP-9607 cells ("P $<0.05$ ).

Table II. Drug sensitivity of the SOSP-9607 and the SOSP-9607/CDDP cells.

\begin{tabular}{lccc}
\hline & \multicolumn{2}{c}{$\mathrm{IC}_{50}($ mean $\pm \mathrm{SD}, \mu \mathrm{g} / \mathrm{ml})$} & \\
\cline { 2 - 3 } Agent & SOSP-9607 & SOSP-9607/DDP & RI \\
\hline CDDP & $2.45 \pm 0.27$ & $15.31 \pm 0.21$ & $6.24^{\mathrm{a}}$ \\
ADM & $3.23 \pm 0.56$ & $6.67 \pm 0.45$ & $2.06^{\mathrm{a}}$ \\
MTX & $11.38 \pm 0.19$ & $20.42 \pm 0.48$ & $1.79^{\mathrm{a}}$ \\
PTX & $0.37 \pm 0.05$ & $0.41 \pm 0.11$ & 1.11 \\
\hline
\end{tabular}

RIs were determined by the ratio of $\mathrm{IC}_{50}$ values of SOSP-9607/DDP to that of SOSP-9607 cells. ${ }^{\mathrm{P}} \mathrm{P}<0.05$, as determined by Student's t-test between the $\mathrm{IC}_{50}$ values of both cell lines. CDDP, cisplatin; ADM, adriamycin; MTX, methotrexate; PTX, paclitaxel; $\mathrm{IC}_{50}, 50 \%$ inhibitory concentration; $\mathrm{SD}$, standard deviation; RI, resistance index.

Invasive capability of the cells. Transwell assays with a layer of Matrigel on the top inserts were performed to examine the invasive capability. After incubation for $48 \mathrm{~h}$, the number of cells that penetrated both the Matrigel and membrane was counted. The results showed that the invasive capability of the SOSP-9607/CDDP cells was increased compared to the invasive capability of the parental SOSP-9607 cells ( $\mathrm{P}<0.01$; Fig. 4).

Expression of drug resistance-related and apoptosis-related genes. Gene expression analysis of MDR1, MRP1, MRP2, LRP, ABCG2, GST- $\pi$, Bcl-2 and Bax is shown in Fig. 5A.
After normalizing the mRNA expression level of each gene relative to that of GAPDH, the levels of MRP1, MRP2 and GST- $\pi$ mRNA in the SOSP-9607/CDDP cells were more highly expressed than those levels in the SOSP-9607 cells $(\mathrm{P}<0.01)$; however, there were no differences in expression for MDR1, LRP, ABCG2, Bcl-2 and Bax mRNA between the SOSP-9607 and SOSP-9607/CDDP cells (Fig. 5B).

\section{Discussion}

Chemotherapy is one of the principal modes of treatment for cancer, yet drug resistance is one of the major impediments for effective chemotherapy in cancer patients. Cancer cells may become cross-resistant to a broad spectrum of chemotherapeutic agents after a single drug treatment, known as multidrug resistance (MDR). MDR can be divided into two broad categories: intrinsic or acquired (6). There are a number of mechanisms known to be involved in cancer drug resistance, such as increased rates of drug efflux, alterations in drug metabolism and mutation of drug targets (7). However, there have been few studies on osteosarcoma drug-resistant cell lines (8-11), which has impeded research on the mechanism of drug resistance of osteosarcoma. The establishment of drug-resistant cancer cell lines is crucial for studying the biological characteristics of resistant cells, the mechanisms of drug resistance and the methods to overcome it. In the present study, we established a CDDP-resistant osteosarcoma cell line in vitro as a model for investigating chemotherapy resistance by intermittent exposure of osteosarcoma parental cells to a high concentration of CDDP with time-stepwise increments. 

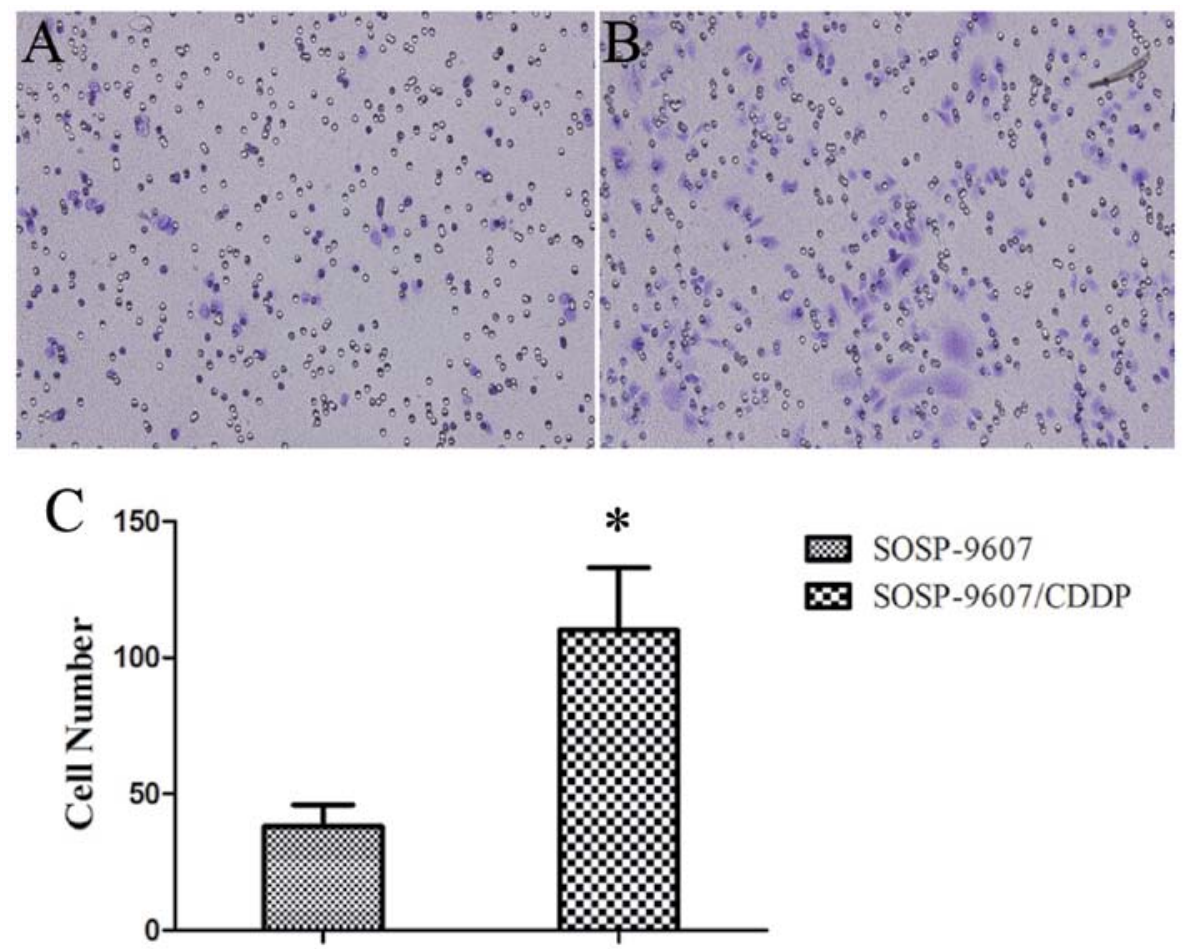

SOSP-9607

$\mathbf{B}$ SOSP-9607/CDDP

Figure 4. Invasive capability of the (A) SOSP-9607 and (B) SOSP-9607/CDDP cells. (C) The invasive capability of the SOSP-9607/CDDP cells was increased compared to that of the parental SOSP-9607 cells ( $\mathrm{P}<0.01)$.

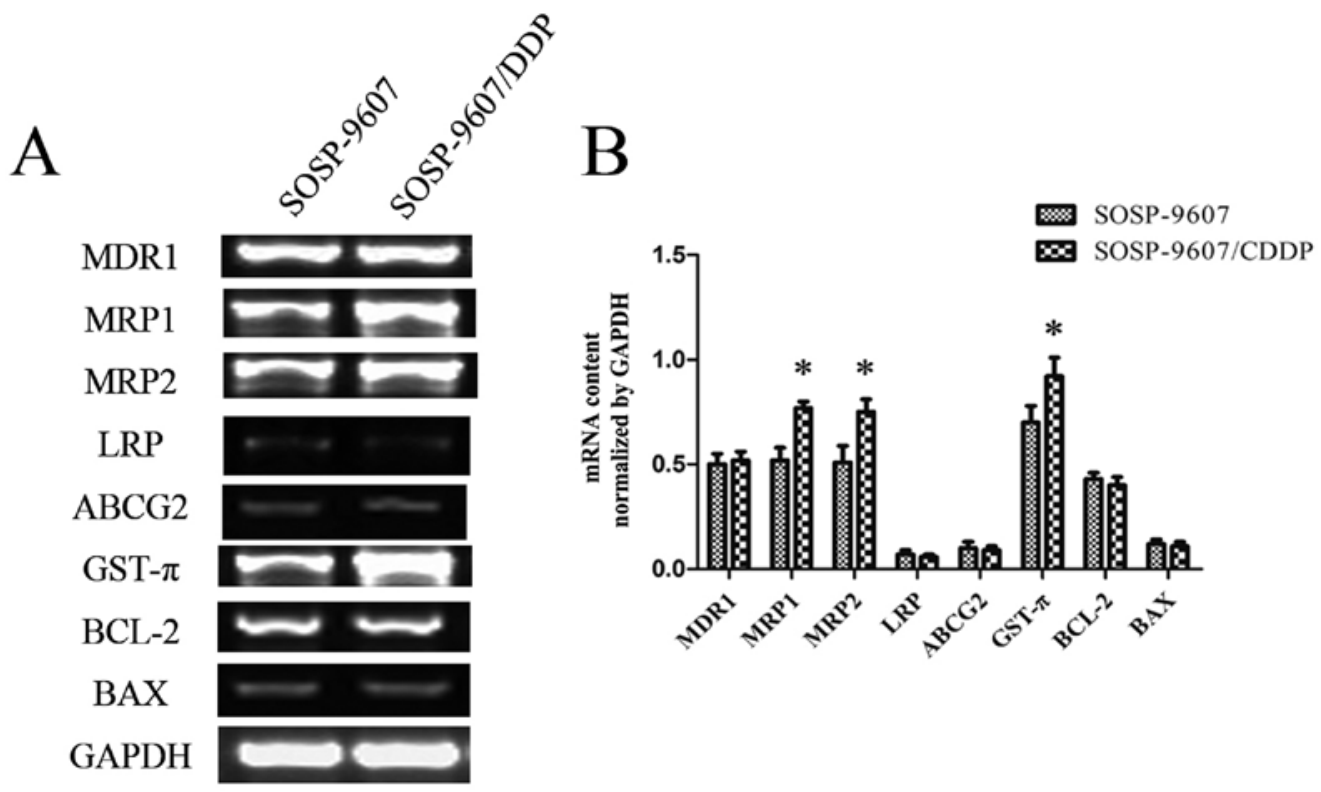

Figure 5. RT-PCR analysis of the SOSP-9607 and SOSP-9607/CDDP cells. (A) Agarose gel electrophoresis image of RT-PCR products for MDR1, MRP1, MRP2, LRP, ABCG2, GST- $\pi$, Bcl-2, Bax and GAPDH. (B) mRNA expression levels of MDR1, MRP1, MRP2, LRP, ABCG2, GST- $\pi$, Bcl-2, Bax after normalization relative to GAPDH. ${ }^{2} \mathrm{P}<0.01$.

After an induction of 12 months, a CDDP-resistant osteosarcoma cell line SOSP-9607/CDDP was established with a typical MDR phenotype. As compared with the parental SOSP-9607 cells, SOSP-9607/CDDP cells showed 6.24-fold resistance to CDDP and cross-resistance to other various drugs, including MTX and ADM. The resistance of SOSP-9607/CDDP cells was not decreased after 3 months of culturing in drug-free medium. This multidrug-resistant characteristic of the SOSP-9607/CDDP cells might imply the failure of chemotherapy combinations of CDDP with other anticancer drugs in clinical practice.

The human osteosarcoma cell line SOSP-9607 was established in our laboratory from a specimen of a 17-year-old patient with pathologically diagnosed osteosarcoma (4). Morphologically, the SOSP-9607/CDDP cells were larger than the SOSP-9607 cells in volume and showed various differences in shape, nucleus and nucleoli. Our results are consistent with those of another study. Wen et al (12) found that these 
ultrastructural changes might facilitate the cisplatin-resistant cell survival after CDDP therapy. Normally, resistant cells should grow faster due to resistance. In this study, the resistant cell line grew slower than the parental cell line and the doubling time of the SOSP-9607/CDDP cells was higher than that of the SOSP-9607 cells (45.11 vs. 29.79 h). Wang et al (13) found that this lower growth of resistant cells might be caused by the existence of non-cycling dormant cells. Our results suggest that after resistance was established, the resistant cells changed their characteristics and lost the majority of the proliferative ability. The growth delay of the SOSP-9607/CDDP cell line warrants further study. Furthermore, the percentages of SOSP-9607/CDDP cells in the $\mathrm{G}_{0} / \mathrm{G}_{1}$ phases were significantly increased when compared with these percentages in the SOSP-9607 cells in the corresponding phases (Fig. 3). There is a critical balance between cell cycle arrest (promoting DNA repair and survival) and cell death following chemotherapy. In response to DNA damage, some genes will be activated or inactivated to induce cell cycle arrest in the $G_{1}$ phase in order to repair damaged DNA (14). A higher proportion of SOSP-9607/CDDP cells was in the $\mathrm{G}_{0} / \mathrm{G}_{1}$ phases, possibly indicating an enhanced capacity in DNA damage repair, which could be considered as a mechanism of drug resistance. The majority of cisplatin DNA damage is removed by the NER system (15). Excision repair cross-complementing rodent repair deficiency, complementation group 1 (ERCC1) participates in the NER system. Bellmunt $e t$ al found that ERCC1 expression was negatively correlated with survival and/or responsiveness to cisplatin-based regimens in several human neoplasms (16). The molecular mechanism of DNA damage repair of the SOSP-9607/CDDP cell line requires further investigation. The results of the invasion assays showed that the invasive capability of the SOSP-9607/CDDP cells was increased compared to that of the parental SOSP-9607 cells $(\mathrm{P}<0.01$; Fig. 4). The increased invasive capability of the SOSP-9607/CDDP cells is involved in tumor metastasis and progression.

The ATP-binding cassette (ABC) transporter family of transmembrane proteins has been linked to resistance to commonly used chemotherapeutics by promoting drug efflux. Several members of this protein family have been studied extensively, such as multidrug resistance protein 1 (MDR1, ABCB1), MDR-associated protein 1 (MRP1, ABCC1) and breast cancer resistance protein (BCRP, ABCG2) (17). Moreover, lung resistance protein (LRP) could confer drug resistance by redistributing drugs away from intracellular targets (18). Therefore, we used RT-PCR to detect the expression levels of these genes in the SOSP-9607 and SOSP9607/CDDP cells. There were no differences in MDR1, LRP and BCRP mRNA expression between the SOSP-9607 and SOSP-9607/CDDP cells; however, MRP1 and MRP2 expression was significantly increased in the SOSP-9607/CDDP cells when compared with that in the SOSP-9607 cells. MRP overexpression is one of the major mechanisms of cisplatin resistance. Borst et al suggested that MRP1, MRP2, MRP3 and MRP5 also mediate some degree of cisplatin resistance by increasing cisplatin export (19). In particular, other reports suggest that MRP2 overexpression is responsible for an increased efflux of cisplatin in resistant cells (20) and MRP2 expression levels might predict the responsiveness of tumors to platinum-based therapies (21). Our results also suggest that drug resistance in the SOSP-9607/CDDP cells might be associated with a mechanism mediated by MRP-induced changes in membrane transport function. It is known that aquated cisplatin avidly binds to cytoplasmic nucleophilic species, such as glutathione (GSH). Elevated levels of GSH and glutathione S-transferase (GST) have been observed in cisplatin-resistant cells, both in vitro and ex vivo (22). Furthermore, Lai et al found that overexpression of GST- $\pi$ increased GST activity in an adriamycin-resistant cell line. Currently, it is generally accepted that increased GST activity is mainly due to overexpression of GST- $\pi$ (23). In the present study, GST $-\pi$ expression was significantly increased in the SOSP9607/CDDP cells when compared with that in the SOSP-9607 cells. These results are consistent with those of another study in two cisplatin-resistant endometrial cancer cell lines (24). Of note, glutathione S-conjugates are readily extruded by cells via MRP1 or MRP2 (25), which possibly explain why MRP expression levels are increased in cisplatin-resistant cells. In short, these findings suggest that the mechanism of drug resistance in SOSP-9607/CDDP cells may be associated with enhanced inactivation of anticancer drugs induced by GST- $\pi$ and increased efflux of drug conjugates induced by MRP1 or MRP2. Recent studies have demonstrated that anticancer drug resistance is induced by mutation of the apoptosis mechanism of cancer cells. Proapoptotic members (Bax, Bak, Bad and Bil) and antiapoptotic members (Bcl-2, Bcl-XL and Mcl-1) of the BCL-2 protein family participate in these lethal cascades, and the majority have been shown to modulate the cellular response to cisplatin. Several studies have found that Bax deficiency and overexpression of BCL-2 conferred resistance to CDDP and to several other stressors in vitro $(26,27)$. In the present study, we compared the expression levels of BCL-2 and Bax in the SOSP-9607 and SOSP-9607/CDDP cells, yet no difference was noted between the resistant cells and the parental cells. However, the level of gene expression did not necessarily parallel with the level of protein. Western blot and protein function assays should be carried out to investigate whether the BCL-2 protein family members participate in the mechanism of resistance to CDDP in SOSP-9607/CDDP cells.

In conclusion, we established the stable SOSP-9607/CDDP drug-resistant osteosarcoma cell line, which showed cross resistance to other drugs. Thus, this cell line could serve as a useful tool for further study concerning the molecular mechanisms of osteosarcoma drug resistance and may lead to the establishment of novel therapeutic strategies for osteosarcoma.

\section{Acknowledgements}

The authors would like to thank Yanhua Wen, Yunyan Liu and Hong Zhao for their excellent technical assistance and helpful discussions. This study was supported by grants from the Postdoctoral Science Foundation of China (no. 2013M532203), Tangdu Hospital Innovation Fund to X.Z. and the National Natural Science Foundation of China (no. 31000660, no. 81372297 and no. 30973409).

\section{References}

1. Gorlick R and Khanna C: Osteosarcoma. J Bone Miner Res 25: 683-691, 2010 
2. Picci P: Osteosarcoma (osteogenic sarcoma). Orphanet J Rare Dis 2: 6, 2007.

3. Negoro K, Yamano Y, Fushimi K, Saito K, Nakatani K, Shiiba M, Yokoe H, Bukawa H, Uzawa K, Wada T, Tanzawa H and Fujita S: Establishment and characterization of a cisplatin-resistant cell line, KB-R, derived from oral carcinoma cell line, KB. Int J Oncol 30: 1325-1332, 2007.

4. Chen X, Yang TT, Wang W, Sun HH, Ma BA, Li CX, Ma Q, Yu Z and Fan QY: Establishment and characterization of human osteosarcoma cell lines with different pulmonary metastatic potentials. Cytotechnology 61: 37-44, 2009.

5. Shibata K, Umezu T, Sakurai M, Kajiyama H, Yamamoto E, Ino K, Nawa A and Kikkawa F: Establishment of cisplatin-resistant ovarian yolk sac tumor cells and investigation of the mechanism of cisplatin resistance using this cell line. Gynecol Obstet Invest 71: 104-111, 2011.

6. Gottesman MM: Mechanisms of cancer drug resistance. Annu Rev Med 53: 615-627, 2002.

7. Holohan C, Van Schaeybroeck S, Longley DB and Johnston PG: Cancer drug resistance: an evolving paradigm. Nat Rev Cancer 13: 714-726, 2013

8. Asada N, Tsuchiya H, Ueda Y and Tomita K: Establishment and characterization of an acquired cisplatin-resistant subline in a human osteosarcoma cell line. Anticancer Res 18: 1765-1768, 1998.

9. Maraldi NM,Zini N, Santi S, Scotlandi K, Serra M and Baldini N: P-glycoprotein subcellular localization and cell morphotype in MDR1 gene-transfected human osteosarcoma cells. Biol Cell 91: $17-28,1999$.

10. Oda Y, Matsumoto Y, Harimaya K Iwamoto Y and Tsuneyoshi M: Establishment of new multidrug-resistant human osteosarcoma cell lines. Oncol Rep 7: 859-866, 2000.

11. Niu BH, Wang JJ, Xi Y and Ji XY: The establishment and characterization of adriamycin-resistant cell lines derived from Saos-2. Med Sci Monit 16: BR184-BR192, 2010.

12. Wen J, Zheng B, Hu Y, Zhang X, Yang H, Luo KJ, Zhang X, $\mathrm{Li} \mathrm{YF}$ and Fu JH: Establishment and biological analysis of the EC109/CDDP multidrug-resistant esophageal squamous cell carcinoma cell line. Oncol Rep 22: 65-71, 2009.

13. Wang C, Guo LB, Ma JY, Li YM and Liu HM: Establishment and characterization of a paclitaxel-resistant human esophageal carcinoma cell line. Int J Oncol 43: 1607-1617, 2013.

14. Longley DB and Johnston PG: Molecular mechanisms of drug resistance. J Pathol 205: 275-292, 2005.

15. Sakai W, Swisher EM, Karlan BY, Agarwal MK, Higgins J, Friedman C, Villegas E, Jacquemont C, Farrugia DJ, Couch FJ, Urban $\mathrm{N}$ and Taniguchi T: Secondary mutations as a mechanism of cisplatin resistance in BRCA2-mutated cancers. Nature 451: $1116-1120,2008$
16. Bellmunt J,Paz-Ares L, Cuello M, Cecere FL, Albiol S, Guillem V, Gallardo E, Carles J, Mendez P, de la Cruz JJ, Taron M, Rosell R and Baselga J; Spanish Oncology Genitourinary Group: Gene expression of ERCC1 as a novel prognostic marker in advanced bladder cancer patients receiving cisplatin-based chemotherapy. Ann Oncol 18: 522-528, 2007.

17. Gottesman MM, Fojo T and Bates SE: Multidrug resistance in cancer: role of ATP-dependent transporters. Nat Rev Cancer 2: 48-58, 2002.

18. Li J, Li ZN, Du YJ, Li XQ, Bao QL and Chen P: Expression of MRP1, BCRP, LRP, and ERCC1 in advanced non-small-cell lung cancer: correlation with response to chemotherapy and survival. Clin Lung Cancer 10: 414-421, 2009.

19. Borst P, Evers R, Kool M and Wijnholds J: A family of drug transporters: the multidrug resistance-associated proteins. J Natl Cancer Inst 92: 1295-1302, 2000

20. Liedert B, Materna V, Schadendorf D, Thomale J and Lage H: Overexpression of cMOAT (MRP2/ABCC2) is associated with decreased formation of platinum-DNA adducts and decreased $\mathrm{G} 2$-arrest in melanoma cells resistant to cisplatin. J Invest Dermatol 121: 172-176, 2003.

21. Yamasaki M, Makino T, Masuzawa T, Kurokawa Y, Miyata H, Takiguchi S, Nakajima K, Fujiwara Y, Matsuura N, Mori M and Doki Y: Role of multidrug resistance protein 2 (MRP2) in chemoresistance and clinical outcome in oesophageal squamous cell carcinoma. Br J Cancer 104: 707-713, 2011.

22. Chen HH and Kuo MT: Role of glutathione in the regulation of cisplatin resistance in cancer chemotherapy. Met Based Drugs 2010: 430939, 2010. doi: 10.1155/2010/430939.

23. Lai GM, Moscow JA, Alvarez MJ, Fojo AT and Bates SE: Contribution of glutathione and glutathione-dependent enzymes in the reversal of adriamycin resistance in colon carcinoma cell lines. Int J Cancer 49: 688-695, 1991.

24. Sagawa Y, Fujitoh A, Nishi H, Ito H, Yudate T and Isaka K: Establishment of three cisplatin-resistant endometrial cancer cell lines using two methods of cisplatin exposure. Tumor Biol 32: 399-408, 2011.

25. Ishikawa T: The ATP-dependent glutathione $\mathrm{S}$-conjugate export pump. Trends Biochem Sci 17: 463-468, 1992.

26. Tajeddine N, Galluzzi L, Kepp O, Hangen E, Morselli E, Senovilla L, Araujo N, Pinna G, Larochette N, Zamzami N, Modjtahedi N, Harel-Bellan A and Kroemer G: Hierarchical involvement of Bak, VDAC1 and Bax in cisplatin-induced cell death. Oncogene 27: 4221-4232, 2008.

27. Jain HV and Meyer-Hermann M: The molecular basis of synergism between carboplatin and ABT-737 therapy targeting ovarian carcinomas. Cancer Res 71: 705-715, 2011. 